\title{
Thyroidectomy in Dilated Cardiomyopathy: A Challenging Case to Anesthesiologist
}

\author{
Erum Ozair, Shagufta Naaz \\ Department of Anaesthesiology, JN Medical College, Aligarh; Uttar Pradesh University of Medical Sciences, Saifai, Uttar Pradesh, \\ India.
}

\section{Corresponding Author: \\ Dr. Erum Ozair \\ Email: erumozair@gmail.com}

This is an Open Access article distributed under the terms of the Creative Commons Attribution License (creativecommons.org/ licenses/by/3.0).

Received Accepted Published

September 30, 2017

February 20, 2018

February 25, 2018

\begin{abstract}
Background: Thyroidectomy is one of the commonest endocrine surgical procedures being carried out throughout the globe. Patients with thyroid disorder and cardiomyopathy are difficult to manage as they may develop complications like difficult airway, thyroid storm, heart failure etc. Restoration of euthyroid state is recommended to prevent thyroid storm. Other goals of anesthetic management are directed towards prevention of myocardial depression, maintenance of euvolemia, stable hemodynamic and management of complications. Case Report: We present a case of 42 years old female having left sided neck swelling which was gradually progressive and associated with chest pain and fatigue with minimal exertion. Conclusion: Anesthetic management of thyroid surgery in dilated cardiomyopathy can be managed by formulating the good anesthetic goals and prompt diagnosis and management of complications.
\end{abstract}

Keywords: Chest Pain, Dilated Cardiomyopathy, Heart Failure, Thyroid Diseases, Thyoidectomy.

\section{Introduction}

Thyroidectomy is one of the most common endocrine surgical procedure being carried out throughout the globe [1,2]. Thyroid disorders make anesthetic management challenging due to potential airway compromise and associated cardiac complications. Majority of these patients have deranged thyroid functions and sometimes may have even malignant changes in the thyroid gland [3]. The commonest implications during such procedures involve the management of a potential difficult airway, especially in cases of retro-sternal goiter, and an enlarged thyroid gland compressing over the trachea for a prolonged duration $[4,5]$.

One of the common cardiac complications associated with thyroid disorders is cardiomyopathy. Cardiomyopathy refers to the deterioration of the function of the myocardium for any reason [3]. Patients with cardiomyopathy are often at risk of dysrhythmias, heart failure or sudden cardiac death.

\section{Case Report}

A 42 years old female presented with left sided neck swelling for 10 years which was gradually progressive and associated with difficulty in swallowing. Patient also complained of choking and difficulty in breathing on lying down for 2-3 months, difficulty in swallowing, loss of weight despite good appetite, fatigue and weakness at rest or with minimal exertion. He also had an associated off and on chest pain for one year. Local neck examination revealed solitary thyroid nodule of size approximately $6.0 \times 4.2 \mathrm{~cm}$ on left side which moves with deglutition but not with protrusion of tongue. Airway examination reveals Mallampati grade II. Vocal cords were normal as seen by indirect laryngoscopy and there was no deviation of trachea. On pre-anaesthestic 
evaluation, pulse rate was $104 / \mathrm{min}$ and regular, blood pressure was $110 / 54 \mathrm{~mm} / \mathrm{Hg}$. Laboratory investigations showed $\mathrm{TSH}=2.4 \mathrm{mU} / \mathrm{L}, \mathrm{T} 4=14 \mu \mathrm{g} /$ $\mathrm{dL}, \mathrm{T} 3=200 \mathrm{ng} / \mathrm{dL}$. Urine routine examination was within normal limits. ECG showed features of left ventricular hypertrophy. 2D echocardiography showed dilated cardiomyopathy (DCM) with severe mitral regurgitation (MR), moderate tricuspid regurgitation (TR) and pulmonary hypertension, left ventricular global hypokinesia and ejection fraction of $24 \%$. Chest radiograph showed moderately enlarged cardiac shadow [Fig.1]. Fine needle aspiration cytology (FNAC) from thyroid nodule revealed hyperplastic thyroid nodule. She was managed pre-operatively with oral propranolol, digoxin, carvedilol, furosemide and spironolactone. Hemi-thyroidectomy was planned after patient was rendered euthyroid.

After taking high risk consent, general anesthesia was planned. Pre-operative assessment revealed: blood pressure (BP) as 118/80 $\mathrm{mm} \mathrm{Hg}$, heart rate (HR) was 70/min and oxygen saturation $\left(\mathrm{SaO}_{2}\right)$ was $95 \%$ on room air. Prior to induction of anesthesia, arterial line and internal jugular central catheter were placed on right side under local anesthesia and other parameters like ECG, end tidal carbon dioxide (EtCO2) and oxygen saturation were also monitored.

Pre-medication was done with dexamethasone $8 \mathrm{mg}$, esmolol $20 \mathrm{mg}$, fentanyl $2.0 \mu \mathrm{g} / \mathrm{kg}$ and midazolam $1.5 \mathrm{mg}$. Patient was preoxygenated with $100 \%$ oxygen for 3-4 minutes and then induced with thiopentone sodium $3-4 \mathrm{mg} / \mathrm{kg}$ till the loss of eye lash reflex. Succinylcholine was administered in dose of $1.5 \mathrm{mg} / \mathrm{kg}$ to facilitate intubation. Then the patient was intubated with cuffed endotracheal tube of $7.0 \mathrm{~mm}$. She was maintained with nitrous oxide $60 \%$, oxygen $40 \%$ and isoflurane. Vecuronium $0.1 \mathrm{mg} / \mathrm{kg}$ was administered initially for neuromuscular paralysis followed by supplemental doses of $0.025 \mathrm{mg} / \mathrm{kg}$ increments.

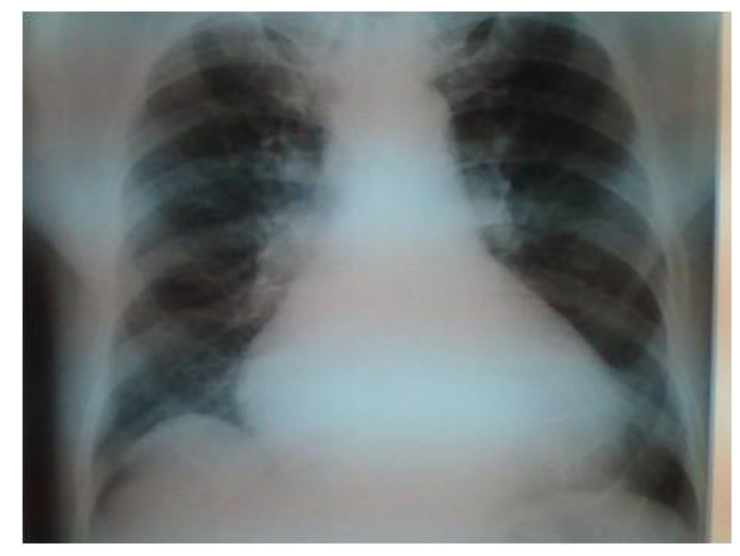

Fig.1: Chest X-ray shows moderate cardiomegaly.

Post-intubation hemodynamic response was minimal as BP was 130/84 $\mathrm{mm} \mathrm{Hg}$ and $\mathrm{HR}$ was $80 / \mathrm{min}$. Intra-operative mean arterial pressure was $65-75 \mathrm{~mm} \mathrm{Hg}$, heart rate $60-71 / \mathrm{min}, \mathrm{SaO}_{2}$ was $99-100 \%$, CVP was $7-10 \mathrm{~cm} \mathrm{H} 2 \mathrm{O}$, end tidal carbon dioxide was $33-37 \mathrm{~mm} \mathrm{Hg}$ and airway pressure was $15-18 \mathrm{~cm} \mathrm{H}_{2} \mathrm{O}$. Intra-operatively patient had a fall of BP to $70 / 45 \mathrm{mmHg}$ and CVP reached $5 \mathrm{mmHg}$, for which dopamine in $5.0 \mu \mathrm{g} /$ $\mathrm{kg} / \mathrm{min}$ and adrenaline in $2.0 \mu \mathrm{g} / \mathrm{min}$ infusion were started. Patient systolic BP was maintained upto $90 \mathrm{mmHg}$ throughout the intra-operative period. Paracetamol $1 \mathrm{gm}$ intravenous was administered intra-operatively for post-operative pain management. $500 \mathrm{ml}$ of crystalloids and $500 \mathrm{ml}$ colloid were given and her total urine output was $200 \mathrm{ml}$ intra-operatively. After that all parameters were under control, surgery lasted for about one hour and hemi-thyroidectomy was completed. At the end of surgery patient was kept electively intubated and was shifted to intensive care unit on ventilator. Patient was extubated on same day after tapering dopamine and adrenaline infusion. She was managed successfully post-operatively and was discharged on $7^{\text {th }}$ post-operative day.

\section{Discussion}

Patients with thyroid disorder and cardiomyopathy are difficult to manage as they may develop complications like difficult airway, thyroid storm, heart failure etc. During any elective thyroid 
surgery, pre-operative optimization of thyroid functions and normalization of thyroid hormone levels are the primary goals to achieve. Without normalizing these hormonal levels, anesthetic agents can be over administered and also leads to high risk of complications like thyroid storm, hypertension and atrial fibrillation [6]. Apart from these, assessment of any difficult airway is also crucial. Incidence of difficult airway during goitre surgery is 5-8\% [3]. Airway assessment can be done by examination of neck which includes movement of neck in all planes, measuring thyromental distance and Mallampatti grading [7].

The common post-operative complications in thyroid surgeries are hemorrhage, thyroid storm, laryngeal edema, superior and recurrent laryngeal nerve damage, tracheomalacia, hypoparathyroidism and pneumothorax. Thyroid storm once occurred can be treated by $\beta$-blockers for tachycardia, cooling of body temperature by adjusting room temperature, ice cold packs, infusion of cold fluids and administering steroids. Other goals of anesthetic management in these patients with associated cardiomyopathy are directed towards prevention of myocardial depression, maintenance of euvolemia, stable hemodynamics and management of complications.

Dilated cardiomyopathy (DCM) is myocardial disease characterized by cardiac enlargement and impaired systolic function of one or both ventricles. Most of the cases are idiopathic, however some known causes include ischemia, valvular dysfunction and post viral infection. There are some associations with DCM like sickle cell disease, excess alcohol, muscular dystrophy, thyroid disorders, chemotherapeutic agents or during peripartum period [8]. DCM is diagnosed if there is ejection fraction $<45 \%$ or fractional myocardial shortening $<25 \%$ and left ventricular end diastolic diameter $>117 \%$ without any other known causes of myocardial diseases. It clinically presents with orthopnea, dyspnea, weakness, fatigue, pedal edema and ascites. Systemic examination can reveal elevated jugular venous distension, pulmonary edema, rales, resting tachycardia, cardiomegaly and S3 \& S4 heart sounds [3,8]. It can present with only cardiomegaly to severe congestive heart failure $(\mathrm{CHF})$. Other presentation includes dysarrhythmias and embolism. Medical management includes with drugs like vasodilator, diuretics or beta blockers and atrio-ventricular pacemakers for patients with incoordinate movements of heart chambers $[9,10,11]$. The optimal time for surgery is difficult to decide but the medical control of heart failure for $>1$ week is desirable.

In patient with left ventricular ejection fraction below 45\%, anesthetic management should be done meticulously. Drugs like ketamine, etomidate and narcotics have minimal depressing effect on cardiac function and are used frequently [9]. In our case we used thiopentone sodium as because of its thioureylene nucleus, it decreases peripheral conversion of $\mathrm{T} 4$ to $\mathrm{T} 3$.

Fluid therapy and medical management is guided by the use of pulmonary artery catheterization and the determination of cardiac filling pressure [12]. Further, continuous monitoring of preload and myocardial performance can be done by trans-esophageal echocardiography (TEE) and cardiac output measurement (CCO) respectively [13]; however these facilities were not available in our setup so we were dependent on central venous pressure.

To counteract the negative effects of anesthetic drugs on heart function, vasoactive or inotropic drugs may be required usually. Due to positive inotropic, chronotropic and vasoconstrictive effects of dopamine, it is an ideal agent to counteract the adverse cardiovascular effects of anesthetics. Our patient had one episode of intra-operative hypotension which may be due to negative effects of anesthetic agents on cardiac function. It was successfully managed by dopamine and adrenaline infusion. Anesthesiologist should also be prepared to use lidocaine, amidarone or defibrillation to treat the arrhythmias [3]. 


\section{Conclusion}

We conclude that anesthetic management of thyroid surgery in patient of thyroid disorder associated with dilated cardiomyopathy is a challenge to the anesthesiologist. These patients can be well managed by thorough preoperative assessment and medical management, formulating the good anesthetic goals and prompt diagnosis and management of complications.

Contributors: EO: Manuscript writing and patient management; SN: manuscript editing. EO will act as guarantor. Both authors approved the final version of this manuscript.

Funding: None; Competing interests: None stated.

\section{References}

1. Dionigi G, Dionigi R, Bartalena L, Tanda ML, Piantanida E, Castano P, et al. Current indications for thyroidectomy. Minerva Chir. 2007;62:359-372

2. Agarwal G, Aggarwal V. Is total thyroidectomy the surgical procedure of choice for benign multinodulargoiter? An evidence-based review. World J Surg. 2008;32:1313-1324.

3. Thiagarajah PH, Thiagarajah S, Frost EAM. Anesthetic considerations in patients with cardiomyopathies - A review. M.E.J. Anesth. 2009;20:347-354.

4. White ML, Doherty GM, Gauger PG. Evidence based surgical management of substernal goiter. World J Surg. 2008;32:1285-300.

5. Bouaggad A, Nejmi SE, Bouderka MA, Abbassi O. Prediction of difficult tracheal intubation in thyroid surgery. Anesth Analg. 2004;99:603-606.

6. Rosato L, Avenia N, Bernante P, De Palma M, Gulino G, Nasi PG, et al. Complications of thyroid surgery: Analysis of a multicentric study on 14,934 patients operated on in Italy over 5 years. World J Surg. 2004;28:271-276.

7. Bajwa SJS, Sehgal V. Anesthesia and thyroid surgery: The never ending challenges. Indian J Endocr Metab. 2013;17:228-234.

8. Katke RD, Ashish Zarariya A. Successful outcome of triplet pregnancy with peripartum cardiomyopathy. Journal of Case Reports. 2014;4:416-418.

9. Kaur H, Khetarpal R, Agarwal S. Dilated cardiomyopathy: An anaesthetic challenge. Journal of Clinical and Diagnostic Research. 2013;7:1174-1176.

10. Stoelting RK, Dierdorf SF. Cardiomyopathy. In: Stoelting RK (ed). Anaesthesia and Coexisting Disease ( $3^{\text {rd }}$ ed). New York: Churchill Livingstone 1993; 97-102.

11. Molhoek SG, Bax JJ, Erven RV. Effectiveness of resynchronization therapy in patients with end stage heart failure. Am J Cardiol. 2002; 90:379-383.

12. Christopher M Bernards. Epidural and Spinal Anaesthesia. In: Clinical Anaesthesia, Lippincot Raven. $3^{\text {rd }}$ Edition 1996; 665.

13. Oda T, Otani S, Yoshimura N. Preanaesthetic evaluation of cardiovascular reserve in a patient with dilated cardiomyopathy. Masui. 1996;45:491-495. 